\title{
Education and Environment Dementia Risk Factors: A Literature Review
}

\author{
Juergen Gallistl
}

\author{
Department of Psychology, University of Vienna, Vienna, Austria
}

\begin{abstract}
Introduction and Background: Dementia has many different causes. Dementia is considered a multifactorial disease; hence the interplay between factors for every case is a complex study. Early and recent reviews had recognised several risk factors associated with dementia in general and with AD specifically. The most studied risk factors include genetics, increasing age, education, environment, and brain injuries. This review aims to give readers access to the latest research on the educational and environmental risk factors of dementia by selecting recent highquality resources and summarising them in this review.
\end{abstract}

Methods: The current article is a narrative review of broad literature research.

Results and Discussion: The comprehensive examination of evidence supports the following. First, low education can be considered a relevant risk factor for developing dementia, although the operationalisation of "low education" is still unclear in many studies. The mechanisms of "cognitive reserve" have an important implication in the relationships between education and dementia, and this has been studied with limitations in people with intellectual disorders. Second, air pollution is now considered a dementia risk factor with plenty of evidence concerning $\mathrm{PM}_{2.5}$ but less conclusive evidence regarding single gaseous pollutants because of the "multi-exposure response."

Conclusion: The considerable body of research points towards an association between these risk factors and dementia prevalence. Low- and middle-income countries will benefit from prioritising child education for all since education is one of the major risk factors for dementia and a wide variety of health disparities.

Keywords: Dementia, Alzheimer's disease, education, environment, risk factors, literature review.

\section{INTRODUCTION}

The number of older people, including those living with dementia, is growing rapidly. Dementia is a public health matter, particularly in under-developing nations, with a significant rise expected in the upcoming generation [1]. At present, there are 50 million cases of $A D$ worldwide. This number is expected to double every five years and reach 150 million by 2050 [2]. The dementia burden of the disease affects not only individuals but their families and the economy in general; only Alzheimer's disease has a global estimated cost of US\$1 trillion annually [3]. With this in mind, the importance of identifying the potentially modifiable risk factors that could reduce dementia including people with intellectual disability- is essential [4].

There are substantial developments in today's understanding of epidemiology, pathogenesis, diagnosis, and psychological consequences of dementia. Early reviews [2,5-8] had recognised several risk factors associated with dementia. Starting with the 1988 review by Henderson et al., over twenty factors and their pathogenesis were discussed [7]. The most studied risk factors include genetics [9], increasing age

*Address correspondence to this author at the Universitätsring 1, 1010 Vienna, Austria, Tel: +4319527024; Fax: +4319527024;

E-mail: juergen.gallistl@gmail.com
[10], education [11], environmental and brain injuries [8]. While dementia in people with intellectual disorders is prevalent, research is limited [12]. The Lancet Commission on Dementia Prevention, Intervention, and Care in 2017 and 2020 conducted a broad review and meta-analyses to identify a 12 risk factor life-course model of dementia prevention [2,5]. Those 12 modifiable risk factors account for around $40 \%$ of worldwide dementias that could theoretically be prevented or delayed [2]. The 12 factors are: low education attainment, hearing impairment, hypertension, traumatic brain injury, alcohol consumption, smoking, obesity, depression, physical inactivity, social isolation, air pollution, and diabetes $[2,5]$. Identifying risk factors has been extensive and is still under development, mainly when keeping up with the high amount of new evidence being published.

Therefore, the purpose of this article is to give readers easy access to the latest research on the educational and environmental risk factors of dementia by selecting high-quality resources that are relevant, meaningful, influential, recent and summarising them into this complete report.

\section{BACKGROUND}

Dementia is a cognitive and memory impairment condition typically present at an older age due to neurological disorders and cerebrovascular 
mechanisms that began at earlier ages [13]. The term "dementia" has been considered stigmatising for certain cultural beliefs, leading to patients avoiding its diagnosis [5,14]. Hence, the Statistical Manual of Mental Disorders (DSM-5) stopped using this term and uses "major neurocognitive disorders" (Major NCD) [15]. This classification differentiates mild and major NCD, which are illnesses characterised by a cognitive decline; however, major NCD, such as dementia, impacts people's daily living and social functioning who have had a normal brain development $[16,17]$.

The progressive decline of cognitive functions can have many different causes, such as Alzheimer's disease (AD), which is the most common, followed by vascular dementia and dementia associated with Lewy bodies (DLB) [5]. Frontotemporal dementia (FTD) is the second cause of pre-senile early-onset dementia $[18,19]$. Dementia featuring a mix of aetiologies is also common, while dementias associated with infections, alcohol abuse, brain injury, abnormality in the pulmonary and circulatory systems, and nutritional deficiency are less frequent causes [20,21]. Furthermore, dementia is prevalent in people with severe or profound intellectual disorders, particularly people with Down syndrome, since they have a high genetic risk of developing dementia $(77 \%$ develop dementia by the age of 69) [12]. Hence, early detection and diagnosis are complex. A pre-existing intellectual disability and co-mobility might mimic dementia symptoms and complicate the diagnosis in this population [22]. According to researchers, the more severe the level of intellectual disorder, the more difficult the diagnosis of dementia is [23].

The DSM-5 describes the criteria to define specific aetiological subtypes of mild and major neurocognitive disorders. The diagnosis is based on clinical characteristics and biomarkers [17]. For the purpose of classifying NCD, the Neurocognitive Disorders Work Group established six principal domains of cognitive function: 1) complex attention, 2) executive function, 3) learning and memory, 4) language, 5) perceptual-motor function, and 6) social cognition. The diagnostic criteria for major NCD or dementia are (A) evidence of significant cognitive decline from a previous level of performance in one or more cognitive domains (the six mentioned above) based on a concern of the person, a knowledgeable informant, or a clinician. Alternatively, a substantial impairment is assessed by standardised neuropsychological testing and clinical assessment. (B) The cognitive decline interferes with independence in everyday activities. (C) The cognitive deficit does not happen only in the context of delirium. (D) The cognitive deficits are not part of another mental disorder (DSM-5

The symptoms start from age 40 to 90 , having no other brain diseases. In 1984 the clinical diagnostic's criteria of $A D$ included the diagnosis of dementia by neurophysiological test, progressive memory loss, impaired daily-life activity, and symptoms such as impairment of language, motor skills disorders, and loss of perception (agnosia) [24]. Later in 2011, the Alzheimer's Association changed the $A D$ dementia criteria to include biomarkers such as markers of brain amyloid, markers of neuronal injury, and magnetic resonance imaging (MRI) for atrophy measurement [25]. Hence, in the case of people with severe intellectual disabilities, the low cognitive baseline functioning makes it difficult to establish a decline from a previously higher level. And the measurable changes using regular neuropsychological tests are not adequate in these cases due to floor effect [12]. While observing the need for daily living is also difficult to observe because some skills were never attained in this population [26].

Dementia is considered a multifactorial disease; hence the interplay between factors for every case is a complex study.

\section{METHODS}

The current study is a narrative literature review. The criteria for high-quality evidence was systematic reviews, randomised clinical trials, and peer-review articles published in high impact factor journals, considered "influencing" when cited more than 300 times. The literature search included the main databases of PubMed (MEDLINE), Web of Science, Scopus, and Google Scholar. The articles did not have a restriction in time, although only articles published in English were included. The search did not follow a systematic approach. However, the keywords used were a combination of Dementia, Alzheimer's disease, education, environment, risk factors and its synonyms.

\section{REVIEW}

\section{Education as a Risk of Dementia}

\section{Education}

The first suggestion about the relationship between dementia and education was done by Mortimer and discussed by Terry \& Davis in 1980 . The proposition was that psychological factors such as education could 
safeguard against dementia by increasing the "intellectual reserve" [20]. Early studies in the 90s suggested the link between low education and dementia [27,28], including the first large-scale study of dementia prevalence conducted in China [29]. The results suggested a strong relationship between lack of any formal education and the increase of dementia prevalence. Nowadays, after 30 years of research, low education is perhaps the most significant modifiable risk worldwide for developing dementia [2,5]. Specifically, higher childhood education levels and higher education attainment are currently recognised as factors for reducing dementia risk [30,31]. New research indicates that cognitive ability increment with education; however, it reaches a plateau in late adolescence when the brain has its greatest plasticity [32]. The studies suggest that education gains are relatively few after the age of 20 concerning dementia protective qualities [2]

Up to 2020 , there was about eight major systematic reviews and meta-analyses that summarise the literature about education and its relationship to dementia, and these are Valenzuela and Sachdev, in 2005 [33]; Caamaño-Isorna et al. in 2006 [34]; Fratiglioni and Wang in 2007 [35]; Sharp and Gatz in 2011 [36]; Meng and D'Arcy in 2012 [37]; Prince et al. in 2014 [38]; Xu et al. in 2016 [39]; Maccora et al. in 2020 [40]. Caamaño-Isorna et al. conducted a metaanalysis with 19 studies where they reported that low education could be considered a risk factor for developing dementia in terms of epidemiological criteria [34]. Five years later, Sharp and Gatz, in a systematic review with 71 studies and 88 study populations, reported that low education was associated in many but not all of the studies; the level of education associated with dementia varied by populations [36].

Odds ratios for low education increasing the risk of dementia were calculated in six meta-analyses [34, 3740], confirming this association. The most recent systematic review and meta-analysis were conducted in 2020 and included 65 studies representing populations from 24 countries [40]. The variable of "education" reported 23 continuous, 29 dichotomous, and 31 categorical operationalisations. Dichotomous operationalisation resulted in the increased risk for low education of $45 \%(95 \% \mathrm{Cl}: 29-63 \%)$ for dementia in general and $85 \%$ (95\% Cl:56-118\%) for AD only. The researchers reported that low education definitions were quite heterogeneous, ranging from zero to 12 years.
In several studies included in the systematic reviews mentioned above, it was unclear what "low education" meant and how much "education" is needed to reduce dementia [41]. As an exception, Meccora et al., in the meta-analysis published in 2020, reported continuous operationalisation of dementia. Each year of education reduced the risk by $8 \%$ for $\mathrm{AD}(95 \% \mathrm{Cl}$ : 5 $12 \%)$ and $7 \%$ for any dementia (95\% Cl:6-9\%) [40]. Another difficulty for measuring this relationship to dementia is that education -and its specific impact- is difficult to separate from the effect of overall cognitive ability and cognitive stimulation [2]. For example, Foverskov et al. in 2020, examined separate and joint associations of adolescent cognitive ability and education attainment with risk of dementia; they found that a $10 \%$ higher cognitive ability score was associated with a $2.8 \%$ lower risk of dementia, while the magnitude of the association only changed marginally after adjustment for education [42]

\section{Cognitive Reserve}

"Reserve" is described as the capacity to maintain cognitive functions relatively well at a given level of pathology. The theory of cognitive reserve (CR) hypothesises that specific life experiences are cognitive stimulating, developing a capability to maintain cognitive performance when ageing and experience certain brain diseases without developing clinical symptoms [43]. A well-documented body of research has pointed towards factors including education, social activities, leisure activities, work complexity which could contribute to this cognitive reserve [35]. Epidemiological studies that support this hypothesis are well established, particularly in $A D$ [44], since patients with neuropathological $A D$ changes do not develop dementia, indicating a type of resilience [45]. However, even when these studies are consistent, there haven't been specific studies involving participants with intellectual disabilities. According to the theory of cognitive reserve, adults with intellectual disabilities would have brain reserve limitations [46]. Furthermore, people with intellectual disabilities in developing countries have been probably excluded from education. This theory predicts that older adults with intellectual disorders are at higher risk for dementia in comparison with their counterparts without disabilities, having a downward shift in age-associated risk [46].

Systematic reviews of epidemiological and biological studies analyse cognitive reserve in dementia, leading to preliminary conclusions. Fratiglioni 
and Wang reported that high education, work complexity and a lifestyle that integrates mental and social activities could postpone the onset of clinical dementia and $A D$ [35]. Cognitive reserve in late life is likely to be increased during early life through education and other intellectual stimulation [31], which impacts neuronal branching and brain plasticity. This reserve, hence, is linked to either brain anatomical substrate or adaptability of cognition [47]. For example, Valenzuela's systematic review found that low educational level results in vulnerability to cognitive decline when there is a lack of CR [33]. However, the current research results are uncertain if education postsecondary school gives additional protective reserve [5], whilst other life experiences such as bilingualism also may be protective considering this a cognitive activity [48]. A recent study in 2021 by Beyer et al. concluded that in patients with frontotemporal dementia (FTD), education level predicts existing hypometabolism at the same cognition level, supporting the theory of $\mathrm{CR}$ also in this type of dementia [49].

\section{Environmental Risk and Dementia}

\section{Air Quality}

Air quality is one of the most important environmental topics of modern times. Each year, both outdoor and indoor air pollution contributes to many diseases' incidence and millions of premature deaths in the entire world. Air pollution includes both solids and gaseous pollutants [50-53]. Solids are particle matter with a diameter less than or equal to specific microns, in specific, particle pollutants $\mathrm{PM}_{10}$ and $\mathrm{PM}_{2.5}$ (aerodynamic diameter $\leq 10 \mathrm{~mm}$ or $\leq 2.5 \mathrm{~mm}$ ). Gaseous are carbon monoxide $(\mathrm{CO})$, nitrogen dioxide $\left(\mathrm{NO}_{2}\right)$, sulfur dioxide $\left(\mathrm{SO}_{2}\right)$, and ozone $\left(\mathrm{O}_{3}\right)$ [54]. A growing body of research indicates that atmosphere quality and pollution affect neuropsychological development and impairment [55]. Although most studies have focused on solids pollutants [56-58], exposure to ambient gaseous pollutants is being studied as a risk of cerebrovascular diseases and ischemic stroke [59]. These diseases relate to dementia prevalence since cerebrovascular diseases are one of the main contributors to Alzheimer's disease and dementia in general [60]. In 2020, the Lancet Commission on Dementia concluded, based on "newer, convincing evidence," that air pollutants, including gaseous, are a dementia risk factor [2]. They also reported that air quality risk might act via vascular mechanisms [61].
Traffic exhaust produces $\mathrm{PM}_{2.5}$ and high nitrogen dioxide $\left(\mathrm{NO}_{2}\right)$ in concentrations more than $>41.5 \mu \mathrm{g} / \mathrm{m}$ that causes damages in human health that are linked to dementia incidence $[62,63]$. The same happens with $\mathrm{PM}_{2.5}$ from residential wood-burning [2]. It is difficult to separate the different pollutants' effects on dementia. Reviews of epidemiological evidence analysing air pollution as a dementia risk factor has described the evidence as "multi-exposure response" or "residual cofounding" $[64,65]$ since other factors such as noise are also considered in traffic $[66,67]$. Overcoming the difficulty of the "multi-exposure" aspect within research, the Lancet Commission on Dementia in 2020, along with other systematic reviews such as Fu and Yung in 2020 [54], Peters et al. in 2019 [61], Tsai et al. in 2019 [68], Paul et al. in 2019 [64], Power et al. in 2016 [69], and Killin et al. also in 2016 [70], concluded that $\mathrm{PM}_{2.5}$, $\mathrm{NO}_{2}$, and carbon monoxide (CO) are all associated with increased dementia risk.

The Lancet Commission on dementia updated the systematic review with research published until October 2019; they included studies with measurements of all causes of air pollution exposure (traffic, household, ambient) and used a formal assessment of cognitive function baseline. The Commission reported all-cause dementia incidents in adults over eighteen years old and a minimum followup of six months. The calculated relative risk (RR) of dementia in the highest quartiles compared with the lowest exposure was reported as 1.09 (1.07-1.11). While the attributable population fraction (PAF) for exposure of $\mathrm{PM}_{2.5}$ and $\mathrm{NO}_{2}$ was $6.1 \%$ (4.8-7.5) [2]. $\mathrm{Fu}$ and Yung conducted a meta-analysis on air pollution and Alzheimer's disease covering studies published until March 2020; they calculated odd risk (OR) for $\mathrm{PM}_{10}, \mathrm{PM}_{2.5}, \mathrm{NO}_{2}, \mathrm{O}_{3}, \mathrm{CO}, \mathrm{SO}_{2}$. The OR per $10 \mathrm{mg} / \mathrm{m}^{3}$ increment of $\mathrm{PM}_{2.5}$ was 1.95 (95\% Cl: 0.88-4.30), suggesting that the association between $A D$ and $\mathrm{PM}_{2.5}$ is strong [54]. The values per $10 \mathrm{mg} / \mathrm{m} 3$ increment of $\mathrm{O}_{3}$ were 1.03 (95\% Cl: 0.68-1.57) and for $\mathrm{NO}_{2}$ were 1.00 (95\% Cl: $0.89-1.13)$. The overall OR for all pollutants with $A D$ was $1.32(95 \% \mathrm{Cl}: 1.09-1.61)$, while heavily polluted regions had an increased risk (2.20) in comparison to lightly polluted regions (1.06).

Finally, in 2021 a new meta-analysis was published by $\mathrm{Ru}$ et al. the authors developed an exposureresponse model and simulation, estimating that ambient $\mathrm{PM}_{2.5}$ pollutions could be responsible for $15 \%$ of premature deaths and $7 \%$ of disability-adjusted life years (DALYs) associated with dementia [71]. In other words, the authors calculated 2.1 million (M) of 
dementia new cases in the over-65 worldwide populations attributable to $\mathrm{PM}_{2.5}$ exposures. Interestingly, the estimates also involved geographic data, suggesting that the largest burden was in China ( $26 \%$ of the global toll); the second and third largest burden was calculated in Japan and India with $8 \%$ each. On a per-capita basis, the greatest incidence and death rates were reported in high-income European and Asian countries due to the older population of these regions and, therefore, a higher baseline incidence rate of dementia [71].

\section{Toxic Metals}

Metals can be found in nature and biological systems; they include bio-metals with a specific function in the organisms and toxicological metals. Among the bio-metals are zinc, iron, and copper [6]. At the same time, toxicological and heavy metals such as aluminium, lead, cadmium, and manganese are widespread in specific environments [72]. Compared with other metals, Aluminium (Al) is the most studied associated with dementia, $A D$, and cognitive functions [73]. Al is frequently used in industries such as foods, medical preparations, cosmetics, and others. Aluminium is transferred via plasma and citrate molecules that mediate its transmission to the brain [74]. There is extensive evidence demonstrating that aluminium accumulation occurs in grey matter in diseases related to Alzheimer's neurofibrillary degeneration [75]. Further studies have indicated that Al also accumulates in the cortex, hippocampus, and cerebellum areas, causing aggregation, misfolding, and phosphorylation in certain proteins such as tau protein, which is a characteristic of $A D$ [74].

Killin et al., in 2016, conducted a systematic review including sixteen publications [70]. They concluded that the only high-quality study was a prospective cohort study called PAQUID [76] with four thousand older adults in France. This study reported that levels higher than $0,1 \mathrm{mg}$ of aluminium consumption in drinking water per day were related to doubling the risk of dementia and three times increase in AD risk [77]. In 2021, Bagepally et al., analysing cognitive functions and $\mathrm{Al}$ exposure, conducted a newer meta-analysis. They reported significant associations of chronic Aluminium exposure and lower global cognitive scores $(-0.65$, 1.09 to -0.22 ) [78]. The specific cognitive domains that were significantly impaired among the population with Al exposure were memory, working memory and processing speed. In addition, Zhang et al. (in 2021) also demonstrated a significant association between $\mathrm{Al}$ exposure and lower cognitive function. They studied workers from aluminium mines and assessed their cognitive functions compared to non-workers. Most of their participants reported a history of dust inhalation when working in the mine and lived in the surrounding area for decades [79].

Although manganese is an essential metal, environmental exposure or high levels in the body can be toxic. Lead and cadmium have been associated with several health problems even when the exposure is low [72]. These three metals had been documented as neurotoxicants, which contribute to AD pathologies [72]. In longitudinal studies with older adults, lead is related to lower cognitive status, and its acute exposure is associated with AD. This metal competes with bio-metals crossing the blood-brain barrier where it can alter neural differentiation, leading to severe damage. However, there is no longitudinal human epidemiology study specifically assessing lead exposure on $A D$.

Cadmium is carcinogenic and can cross the bloodbrain barrier and lead to neurological diseases, including $A D$ [80]. Cadmium exposure usually occurs through diet and smoking cigarettes; the last one can enter the brain via the olfactory bulb and through the blood-cerebrospinal fluid barrier [72], causing neuroinflammation and oxidative stress. This metal also can change the permeability of the blood-brain barrier leading to tau neurofibrillary tangles; this is associated with decreased cognitive function and $A D$. On the other hand, manganese is an essential metal usually ingested through the diet, although high levels via inhalation can cause its accumulation. Manganese ingested in the diet can also cross the blood-brain barrier, while inhaled manganese is absorbed through olfactory transports pathways leading to brain accumulation [72]. In human epidemiologic research, elevated exposure is related to cognitive decline and neurodegenerative disease.

\section{DISCUSSION}

The comprehensive examination of evidence regarding the educational and environmental risk factors of dementia supports the following. First, low education can be considered a relevant risk factor for developing dementia, although the operationalisation of "low education" is still unclear in many studies. In addition, the mechanisms of "cognitive reserve" have an important implication in the relationships between education and dementia. Second, air pollution is now 
considered a dementia risk factor with plenty of evidence concerning $\mathrm{PM}_{2.5}$ but less conclusive evidence regarding single gaseous pollutants because of the "multi-exposure response." In the following section, we will expand on the complexity of the research evidence.

A large body of research supports a causal association between education and dementia [81]. Moreover, as Meccora et al. pointed out, the effect of education on dementia is outstanding given the heterogeneity of measurements, the different types of dementia, population diversity, diagnostic methods, and statistical approach of the studies [40]. In countries such as the United States, Sweden, Netherlands, and Canada, there was an unexpected decline in agespecific dementia prevalence has observed $[82,83]$; the studies suggest that the increment of education in the general population might be the cause [84]. However, even if education is an important modifiable risk factor $[2,5]$, there is a lack of consensus about the definition of "low education."

Maccora et al. in 2020 published a systematic review documenting the inconsistency in measuring and operationalising education in dementia research specifically. There were studies with continuous, dichotomous and categorical operationalisations of education in their review. Many of the studies in the review defined the variable in terms of years; however, the cut-offs used for "low education" ranged from zero to twelve years of study. The rest of the studies used levels of attainment, but the cut-off considered "low" ranged from not completing primary school, elementary school, high school, or not having any qualification. Interestingly, the authors concluded that the education measurement would differ depending on the theoretical framework the study is looking from. For example, a neuroscientific perspective would have the objective of measuring the total neuroprotective exposure (years of study), a psychological viewpoint would be interesting in measuring the overall level of achievement because the psychosocial characteristics, while a sociological standpoint, would want to develop a measure that represents a socioeconomic milestone that changes the opportunities and lifestyle [40]. The authors concluded that measurement and definition of education obstruct the translation of evidence into practice, delaying the design of policy recommendations and strategies to reduce dementia risk [40].

Reed et al. adopted a "residual approach," which is proposed as a quantitative index for cognitive reserve in patients with $A D$. The central concept is that "reserve" could be defined as the "difference between the cognitive performance predicted by an individual's level of pathology and that individual's actual performance." Using this concept, people whose cognitive performance is superior to the predicted by the pathology have a high reserve, whereas people who perform poorer than predicted have a low reserve [85]. This framework has been helpful as an index in several studies $[33,35,49,86]$. However, one weakness of this method is that the residual may result from a mixture of random prediction error, and then a portion of the variable could be attributed to reserve.

As pointed out earlier, given the heterogeneity and multidisciplinary proxy variable of education, it is difficult to predict how education impacts cognitive reserve. Sharp and Gatz have suggested that "education is best described as a proxy for a trajectory of life events... that either increase or decrease an individual's risk for dementia" [36]. Furthermore, as Beyer et al. point out, years of education is not the only proxy that has been recognised to assess cognitive reserve [49]; other factors such as occupation and life activities have been recognised as contributors to the overall reserve of a person $[43,87]$. Livingston et al. in the Lancet Commission on dementia also explained that cognitive reserve is changeable, and it uses proxy measures such as residual approach, education, the complexity of occupation, and life activities [88-90]. For example, people in higher cognitively demanding jobs tend to show less cognitive deterioration before and even after retirement [91]. Although there is conflicting evidence in this regard, one longitudinal study with more than a thousand people found older retirement age associated with lower dementia risk, but not the number of years working or the type of work [92].

There is some contradictory evidence regarding air quality because it has been suggested that traffic and air pollution in association with dementia might not be considered the co-pollution effects. And multi-exposure to simultaneously factors such as noise and lack of greenness which also have been studied to be related to the incidence of dementia. For example, Yuchi et al. in 2020 studied how greenness could have a protective effect from cognitive deterioration, while road proximity accounts not only for air pollution but also noise [67].

As Livingston et al. point out, the attributable population fraction (PAF) assumes an association between a risk factor and dementia incidence; however, a causative link is needed for leading 
interventions to actual incidence reduction. In addition, causality would need a higher level of evidence, such as randomised controlled trials with humans, and some authors have suggested that correlation could not be reliably interpreted as evidence of a causal relationship because of the potential confounding [81]. On the contrary, since human randomised controlled trials are not viable for certain risk factors, several authors have recommended using "association" as a criterion for causality [93].

\section{CONCLUSION}

This review explored and discussed the latest highquality research on the educational and environmental risk factors of dementia and was summarised them into this complete review.

The Lancet Commission on Dementia Prevention, Intervention, and Care identified 12 modifiable risk factors, which account for around $40 \%$ of worldwide dementias that could theoretically be prevented or delayed. Among those are low education and air pollution. Odds ratios had been calculated in several meta-analyses confirming that low education increases the risk of dementia. These results are outstanding given the heterogeneity of the operationalisation of education, the types of dementia, the population diversity, diagnosis methods and research methodology. Regarding the heterogeneity of the "low education concept," there are inconsistencies where studies account for years of study or educational attainment. One of the standard theories used to explain this relationship is the "cognitive reserve" approach. It was observed that low education level results in the vulnerability of cognitive decline. Furthermore, systematic reviews suggest that cognitive reserve in dementia is not only attained by education, work complexity, and life activities, and other factors are also recognised as contributors of cognitive reserve. At the same time, this theory has been studied with limitations in people with intellectual disabilities.

In regards to environmental risk factors, air pollution, which encompasses solids and gaseous pollutants such as $\mathrm{PM}_{2.5}$ carbon monoxide (CO), nitrogen dioxide $\left(\mathrm{NO}_{2}\right)$, sulfur dioxide $\left(\mathrm{SO}_{2}\right)$, and ozone $\left(\mathrm{O}_{3}\right)$, had been associated with cognition impairment. Specifically, exposure to $\mathrm{PM}_{2.5}$ is now well recognised as a dementia risk factor although, it is difficult to separate the effects of the different pollutants. This problem is best described as a multi-exposure response since air pollution encompasses several pollutants and is present with other factors such as noise. Amongst toxic metals, aluminium (Al) is the most studied metal. Al exposure has been found to be associated with dementia, $A D$, and cognitive impairment. There is extensive evidence that $\mathrm{Al}$ accumulates in specific brain areas and causes neurofibrillary degeneration.

The considerable body of research points towards an association between these risk factors and dementia incidence and prevalence. Further, low- and middle-income countries will benefit from prioritising child education for all since education is one of the major risk factors for dementia and a wide variety of health disparities.

\section{FUNDING}

This work was self-financed.

\section{CONFLICT OF INTEREST}

The author confirms that there is no conflict of interest.

\section{ACKNOWLEDGEMENTS}

Initial idea and article writing by JG. The author thanks Tulia González for their editorial contributions.

\section{REFERENCES}

[1] Prince MJ, Wimo A, Guerchet MM, Ali GC, Wu Y-T, Prina M. World Alzheimer Report 2015 - The Global Impact of Dementia: An analysis of prevalence, incidence, cost and trends. 2015 Aug [cited 2021 Jul 18]; Available from: https://kclpure.kcl.ac.uk/portal/en/publications/world-alzheimerreport-2015--the-global-impact-of-dementia(ae525fda-19384892-8daa-a2222a672254).html

[2] Livingston G, Huntley J, Sommerlad A, Ames D, Ballard C Banerjee $\mathrm{S}$, et al. Dementia prevention, intervention, and care: 2020 report of the Lancet Commission. The Lancet 2020; 396(10248): 413-46 https://doi.org/10.1016/S0140-6736(20)30367-6

[3] Yiannopoulou KG, Papageorgiou SG. Current and future treatments in Alzheimer Disease: An update. J Cent Nerv Syst Dis 2020; 12: 1179573520907397. https://doi.org/10.1177/1179573520907397

[4] Anstey KJ, Ee N, Eramudugolla R, Jagger C, Peters R. A Systematic Review of Meta-Analyses that Evaluate Risk Factors for Dementia to Evaluate the Quantity, Quality, and Global Representativeness of Evidence. J Alzheimer's Dis 2019; 70(s1): S165-86. https://doi.org/10.3233/JAD-190181

[5] Livingston G, Sommerlad A, Orgeta V, Costafreda SG, Huntley J Ames $\mathrm{D}$, et al. Dementia prevention, intervention, and care. The Lancet 2017; 390(10113): 2673-734 https://doi.org/10.1016/S0140-6736(17)31363-6

[6] Breijyeh Z, Karaman R. Comprehensive review on Alzheimer's Disease: Causes and treatment. Molecules 2020; 25(24): 5789. https://doi.org/10.3390/molecules 25245789

[7] Henderson AS. The risk factors for Alzheimer's disease: A review and a hypothesis. Acta Psychiatrica Scandinavica 1988; 78(3): 257-75.

https://doi.org/10.1111/j.1600-0447.1988.tb06336.x 
[8] A Armstrong R. Risk factors for Alzheimer's disease. Folia Neuropathol 2019; 57(2): 87-105. https://doi.org/10.5114/fn.2019.85929

[9] Van Cauwenberghe C, Van Broeckhoven C, Sleegers K. The genetic landscape of Alzheimer disease: Clinical implications and perspectives. Genet Med 2016; (5): 421-30. https://doi.org/10.1038/gim.2015.117

[10] Hou Y, Dan X, Babbar M, Wei Y, Hasselbalch SG, Croteau DL, et al. Ageing as a risk factor for neurodegenerative disease. Nat Rev Neurol 2019;15(10): 565-81. https://doi.org/10.1038/s41582-019-0244-7

[11] Jonaitis E, La Rue A, Mueller KD, Koscik RL, Hermann B, Sager MA. Cognitive activities and cognitive performance in middleaged adults at risk for Alzheimer's disease. Psychol Aging 2013; 28(4): 1004-14.

https://doi.org/10.1037/a0034838

[12] Wissing MBG, Ulgiati AM, Hobbelen JSM, De Deyn PP, Waninge A, Dekker AD. The neglected puzzle of dementia in people with severe/profound intellectual disabilities: A systematic literature review of observable symptoms. J Appl Res Intellect Disabil 2022; 35(1): 24-45.

https://doi.org/10.1111/jar.12920

[13] Whalley L. Understanding Brain Aging and Dementia [Internet]. Understanding Brain Aging and Dementia. Columbia University Press; 2015 [cited 2021 Jul 18].

\section{https://doi.org/10.7312/whal16382}

[14] Mukadam N, Livingston G. Reducing the stigma associated with dementia: approaches and goals. Aging Health 2012; 8(4): 37786.

\section{https://doi.org/10.2217/ahe.12.42}

[15] Blazer D. Neurocognitive Disorders in DSM-5. AJP 2013; 170(6): 585-7. https://doi.org/10.1176/appi.aip.2013.13020179

[16] World Health Organization. International Statistical Classification of Diseases and Related Health Problems 10th Revision. WHO 2016.

[17] Sachdev PS, Blacker D, Blazer DG, Ganguli M, Jeste DV, Paulsen JS, et al. Classifying neurocognitive disorders: The DSM-5 approach. Nat Rev Neurol 2014; 10(11): 634-42. https://doi.org/10.1038/nrneurol.2014.181

[18] Vieira RT, Caixeta L, Machado S, Silva AC, Nardi AE, AriasCarrión $\mathrm{O}$, et al. Epidemiology of early-onset dementia: A review of the literature. Clin Pract Epidemiol Ment Health 2013; 9: 88-95. https://doi.org/10.2174/1745017901309010088

[19] Lambert MA, Bickel H, Prince M, Fratiglioni L, Strauss EV, Frydecka D, et al. Estimating the burden of early-onset dementia; systematic review of disease prevalence. Eur J Neurol 2014; 21(4): 563-9.

https://doi.org/10.1111/ene.12325

[20] Terry RD, Davies P. Dementia of the Alzheimer type. Annu Rev Neurosci 1980; 3(1): 77-95.

https://doi.org/10.1146/annurev.ne.03.030180.000453

[21] Stevens T, Livingston G, Kitchen G, Manela M, Walker Z, Katona C. Islington study of dementia subtypes in the community. $\mathrm{Br} \mathrm{J}$ Psychiatry 2002; 180(3): 270-6. https://doi.org/10.1192/bip.180.3.270

[22] McKenzie K, Metcalfe D, Murray G. A review of measures used in the screening, assessment and diagnosis of dementia in people with an intellectual disability. J Appl Res Intellect Disabil 2018; 31(5): 725-42. https://doi.org/10.1111/jar.12441

[23] Evans E, Bhardwaj A, Brodaty H, Sachdev P, Draper B, Trollor JN. Dementia in people with intellectual disability: Insights and challenges in epidemiological research with an at-risk population. Int Rev Psychiatry 2013; 25(6): 755-63. https://doi.org/10.3109/09540261.2013.866938

[24] McKhann G, Drachman D, Folstein M, Katzman R, Price D, Stadlan EM. Clinical diagnosis of Alzheimer's disease: report of the NINCDS-ADRDA Work Group under the auspices of Department of Health and Human Services Task Force on Alzheimer's Disease. Neurology 1984; 34(7): 939-44. https://doi.org/10.1212/WNL.34.7.939
[25] McKhann GM, Knopman DS, Chertkow H, Hyman BT, Jack CR Kawas $\mathrm{CH}$, et al. The diagnosis of dementia due to Alzheimer's disease: Recommendations from the National Institute on AgingAlzheimer's Association workgroups on diagnostic guidelines for Alzheimer's disease. Alzheimer's Dement 2011; 7(3): 263-9. https://doi.org/10.1016/i.jalz.2011.03.005

[26] Sheehan R, Sinai A, Bass N, Blatchford P, Bohnen I, Bonell S, et al. Dementia diagnostic criteria in Down syndrome. Int J Geriatr Psychiatry 2015; 30(8): 857-63.

https://doi.org/10.1002/gps.4228

[27] Katzman R. Education and the prevalence of dementia and Alzheimer's disease. Neurology 1993; 43(1): 13-20. https://doi.org/10.1212/WNL.43.1 Part 1.13

[28] Mortimer JA, Graves AB. Education and other socioeconomic determinants of dementia and Alzheimer's disease. Neurology 1993; 43(8, Suppl 4): S39-S44.

[29] Zhang M, Katzman R, Salmon D, Jin H, Cai G, Wang Z, et al. The prevalence of dementia and Alzheimer's disease in Shanghai, China: Impact of age, gender, and education. Ann Neurol 1990; 27(4): 428-37. https://doi.org/10.1002/ana.410270412

[30] Satizabal CL, Beiser AS, Chouraki V, Chêne G, Dufouil C Seshadri S. Incidence of Dementia over Three Decades in the Framingham Heart Study. New Eng J Med 2016; 374(6): 523-32. https://doi.org/10.1056/NEJMoa1504327

[31] Larsson SC, Traylor M, Malik R, Dichgans M, Burgess S, Markus HS. Modifiable pathways in Alzheimer's disease: Mendelian randomisation analysis. BMJ 2017; 359: j5375. https://doi.org/10.1136/bmj.j5375

[32] Kremen WS, Beck A, Elman JA, Gustavson DE, Reynolds CA $\mathrm{Tu} \mathrm{XM}$, et al. Influence of young adult cognitive ability and additional education on later-life cognition. PNAS 2019; 116(6): 2021-6.

https://doi.org/10.1073/pnas.1811537116

[33] Valenzuela MJ, Sachdev P. Brain reserve and dementia: a systematic review. Psychol Med 2006; 36(4): 441-54. https://doi.org/10.1017/S0033291705006264

[34] Caamaño-Isorna F, Corral M, Montes-Martínez A, Takkouche B. Education and Dementia: A Meta-Analytic Study. NED 2006; 26(4): 226-32. https://doi.org/10.1159/000093378

[35] Fratiglioni L, Wang H-X. Brain Reserve Hypothesis in Dementia. J Alzheimer's Dis 2007; 12(1): 11-22. https://doi.org/10.3233/JAD-2007-12103

[36] Sharp ES, Gatz M. The Relationship between Education and Dementia An Updated Systematic Review. Alzheimer Dis Assoc Disord 2011; 25(4): 289-304. https://doi.org/10.1097/WAD.0b013e318211c83c

[37] Meng X, D'Arcy C. Education and Dementia in the Context of the Cognitive Reserve Hypothesis: A Systematic Review with MetaAnalyses and Qualitative Analyses. PLOS ONE 2012; 7(6): e38268. https://doi.org/10.1371/journal.pone.0038268

[38] Prince M, Acosta D, Ferri CP, Guerra M, Huang $Y$, Rodriguez $\mathrm{JJL}$, et al. Dementia incidence and mortality in middle-income countries, and associations with indicators of cognitive reserve: A 10/66 Dementia Research Group population-based cohort study. Lancet 2012; 380(9836): 50-8. https://doi.org/10.1016/S0140-6736(12)60399-7

[39] Xu W, Tan L, Wang H-F, Tan M-S, Tan L, Li J-Q, et al. Education and Risk of Dementia: Dose-Response Meta-Analysis of Prospective Cohort Studies. Mol Neurobiol 2016; 53(5): 3113-23. https://doi.org/10.1007/s12035-015-9211-5

[40] Maccora J, Peters R, Anstey KJ. What does (low) education mean in terms of dementia risk? A systematic review and metaanalysis highlighting inconsistency in measuring and operationalising education. SSM Popul Health 2020; 12: 100654. https://doi.org/10.1016/i.ssmph.2020.100654

[41] Then FS, Luck T, Angermeyer MC, Riedel-Heller SG. Education as protector against dementia, but what exactly do we mean by education? Age Ageing 2016; 45(4): 523-8. https://doi.org/10.1093/ageing/afw049 
[42] Foverskov E, Glymour MM, Mortensen EL, Osler M, Okholm GT, Lund $R$. Education and adolescent cognitive ability as predictors of dementia in a cohort of Danish men. PLoS One 2020; 15(8): e0235781. https://doi.org/10.1371/journal.pone.0235781

[43] Stern Y, Alexander GE, Prohovnik I, Mayeux R. Inverse relationship between education and parietotemporal perfusion deficit in Alzheimer's disease. Ann Neurol 1992; 32: 371-5. https://doi.org/10.1002/ana.410320311

[44] Stern Y. Cognitive reserve in ageing and Alzheimer's disease. Lancet Neurol 2012; 11(11): 1006-12. https://doi.org/10.1016/S1474-4422(12)70191-6

[45] SantaCruz KS, Sonnen JA, Pezhouh MK, Desrosiers MF, Nelson PT, Tyas SL. Alzheimer Disease Pathology in Subjects Without Dementia in 2 Studies of Aging: The Nun Study and the Adult Changes in Thought Study. J Neuropathol Exp Neurol 2011; 70(10): $832-40$

https://doi.org/10.1097/NEN.0b013e31822e8ae9

[46] Strydom A, Hassiotis A, King M, Livingston G. The relationship of dementia prevalence in older adults with intellectual disability (ID) to age and severity of ID. Psychol Med 2009; 39(1): 13-21. https://doi.org/10.1017/S0033291708003334

[47] Amieva H, Mokri H, Le Goff M, Meillon C, Jacqmin-Gadda $H$, Foubert-Samier A, et al. Compensatory mechanisms in highereducated subjects with Alzheimer's disease: a study of 20 years of cognitive decline. Brain 2014; 137(4): 1167-75 https://doi.org/10.1093/brain/awu035

[48] Sanders AE, Hall CB, Katz MJ, Lipton RB. Non-Native Language Use and Risk of Incident Dementia in the Elderly. J of Alzheimer's Disease 2012; 29(1): 99-108. https://doi.org/10.3233/JAD-2011-111631

[49] Beyer L, Meyer-Wilmes J, Schönecker S, Schnabel J, Sauerbeck $\mathrm{J}$, Scheifele $\mathrm{M}$, et al. Cognitive reserve hypothesis in frontotemporal dementia: A FDG-PET study. Neuroimage Clin 2021; 29: 102535

https://doi.org/10.1016/i.nicl.2020.102535

[50] Dickey JH. Selected topics related to occupational exposures Part VII. Air pollution: Overview of sources and health effects. Disease-a-Month 2000; 46(9): 566-89. https://doi.org/10.1016/S0011-5029(00)90024-5

[51] Lewtas J. Air pollution combustion emissions: Characterisation of causative agents and mechanisms associated with cancer, reproductive, and cardiovascular effects. Mutat Res/Rev Mutat Res 2007; 636(1): 95-133.

https://doi.org/10.1016/j.mrrev.2007.08.003

[52] Wu Y-C, Lin Y-C, Yu H-L, Chen J-H, Chen T-F, Sun Y, et al. Association between air pollutants and dementia risk in the elderly. Alzheimer's \& Dementia: Diagnosis, Assess Dis Monit 2015; 1(2): 220-8 https://doi.org/10.1016/i.dadm.2014.11.015

[53] Jung C-R, Lin Y-T, Hwang B-F. Ozone, Particulate Matter, and Newly Diagnosed Alzheimer's Disease: A Population-Based Cohort Study in Taiwan. J Alzheimer's Dis 2015; 44(2): 573-84. https://doi.org/10.3233/JAD-140855

[54] Fu P, Yung KKL. Air Pollution and Alzheimer's Disease: A Systematic Review and Meta-Analysis. J Alzheimers Dis 2020; 77(2): 701-14 https://doi.org/10.3233/JAD-200483

[55] Guxens M, Sunyer J. A review of epidemiological studies on neuropsychological effects of air pollution. Swiss Medical Weekly [Internet]. 2012 Jan 1 [cited 2021 Sep 12];(1). Available from: https://smw.ch/article/doi/smw.2012.13322

[56] Chang K-H, Chang M-Y, Muo C-H, Wu T-N, Chen C-Y, Kao C-H. Increased Risk of Dementia in Patients Exposed to Nitrogen Dioxide and Carbon Monoxide: A Population-Based Retrospective Cohort Study. Plos One 2014; 9(8): e103078. https://doi.org/10.1371/journal.pone.0103078

[57] Weuve J, Puett RC, Schwartz J, Yanosky JD, Laden F, Grodstein F. Exposure to Particulate Air Pollution and Cognitive Decline in Older Women. Arch Inter Med 2012; 172(3): 219-27.

https://doi.org/10.1001/archinternmed.2011.683

[58] Ranft U, Schikowski T, Sugiri D, Krutmann J, Krämer U. Longterm exposure to traffic-related particulate matter impairs cognitive function in the elderly. Environ Res 2009; 109(8): 100411. https://doi.org/10.1016/j.envres.2009.08.003

[59] Turin TC, Kita Y, Rumana N, Nakamura Y, Ueda K, Takashima $\mathrm{N}$, et al. Ambient Air Pollutants and Acute Case-Fatality of Cerebro-Cardiovascular Events: Takashima Stroke and AMI Registry, Japan (1988-2004). CED 2012; 34(2): 130-9. https://doi.org/10.1159/000339680

[60] Kokmen E, Whisnant JP, O'Fallon WM, Chu C-P, Beard CM. Dementia after ischemic stroke: A population-based study in Rochester, Minnesota (1960-1984). Neurology 1996; 46(1): 1549. https://doi.org/10.1212/WNL.46.1.154

[61] Peters R, Ee N, Peters J, Booth A, Mudway I, Anstey KJ. Air Pollution and Dementia: A Systematic Review. J Alzheimers Dis 2019; 70(s1): S145-63. https://doi.org/10.3233/JAD-180631

[62] Chen H, Kwong JC, Copes R, Tu K, Villeneuve PJ, van Donkelaar $\mathrm{A}$, et al. Living near major roads and the incidence of dementia, Parkinson's disease, and multiple sclerosis: a population-based cohort study. The Lancet 2017; 389(10070): 718-26. https://doi.org/10.1016/S0140-6736(16)32399-6

[63] Power MC, Weisskopf MG, Alexeeff SE, Coull BA, Spiro AI, Schwartz J. Exposure to Black Carbon and Cognitive Function in a Cohort of Older Men. Epidemiology 2011; 22(1): S203. https://doi.org/10.1097/01.ede.0000392306.56000.80

[64] Paul KC, Haan M, Mayeda ER, Ritz BR. Ambient Air Pollution, Noise, and Late-Life Cognitive Decline and Dementia Risk. Annu Rev Public Health 2019; 40(1): 203-20. https://doi.org/10.1146/annurev-publhealth-040218-044058

[65] Carey IM, Anderson HR, Atkinson RW, Beevers SD, Cook DG, Strachan DP, et al. Are noise and air pollution-related to the incidence of dementia? A cohort study in London, England. BMJ Open 2018; 8(9): e022404. https://doi.org/10.1136/bmjopen-2018-022404

[66] Oudin A. Short review: Air pollution, noise and lack of greenness as risk factors for Alzheimer's disease- epidemiologic and experimental evidence. Neurochem Int 2020; 134: 104646. https://doi.org/10.1016/j.neuint.2019.104646

[67] Yuchi W, Sbihi H, Davies H, Tamburic L, Brauer M. Road proximity, air pollution, noise, green space and neurologic disease incidence: a population-based cohort study. Environ Health 2020; 19(1): 8. https://doi.org/10.1186/s12940-020-0565-4

[68] Tsai T-L, Lin Y-T, Hwang B-F, Nakayama SF, Tsai C-H, Sun X-L, et al. Fine particulate matter is a potential determinant of Alzheimer's disease: A systemic review and meta-analysis. Environ Res 2019; 177: 108638. https://doi.org/10.1016/i.envres.2019.108638

[69] Power MC, Adar SD, Yanosky JD, Weuve J. Exposure to air pollution as a potential contributor to cognitive function, cognitive decline, brain imaging, and dementia: A systematic review of epidemiologic research. NeuroToxicology 2016; 56: 235-53. https://doi.org/10.1016/j.neuro.2016.06.004

[70] Killin LOJ, Starr JM, Shiue IJ, Russ TC. Environmental risk factors for dementia: a systematic review. BMC Geriatr 2016; 16(1): 175.

https://doi.org/10.1186/s12877-016-0342-y

[71] Ru M, Brauer M, Lamarque J-F, Shindell D. Exploration of the Global Burden of Dementia Attributable to PM2.5: What Do We Know Based on Current Evidence? Geohealth 2021; 5(5): e2020GH000356. https://doi.org/10.1029/2020GH000356

[72] Bakulski KM, Seo YA, Hickman RC, Brandt D, Vadari HS, Hu H et al. Heavy Metals Exposure and Alzheimer's Disease and Related Dementias. J Alzheimers Dis. 2020;76(4):1215-42. https://doi.org/10.3233/JAD-200282

[73] Emard JF, Andre P, Thouez J-P, Mathieu J, Boily C, Beaudry M, et al. Geographical distribution of Alzheimer's disease cases at birth and the geochemical profile of Saguenay-Lac-SaintJean/Québec, Canada (image project). Water Air Soil Pollut 1994; 72(1): 251-64.

https://doi.org/10.1007/BF01257128 
[74] Colomina MT, Peris-Sampedro F. Aluminum and Alzheimer's Disease. Adv Neurobiol 2017; 18: 183-97. https://doi.org/10.1007/978-3-319-60189-2__

[75] McLachlan DR. Aluminum and Alzheimer's disease. Neurobiol Aging 1986; 7(6): 525-32 https://doi.org/10.1016/0197-4580(86)90102-8

[76] Dartigues JF, Gagnon M, Michel P, Letenneur L, Commenges D, Barberger-Gateau $\mathrm{P}$, et al. The Paquid research program on the epidemiology of dementia. Methods and initial results. Rev Neurol (Paris) 1991; 147(3): 225-30.

[77] Rondeau V, Jacqmin-Gadda $H$, Commenges D, Helmer C, Dartigues J-F. Aluminum and silica in drinking water and the risk of Alzheimer's disease or cognitive decline: findings from 15-year follow-up of the PAQUID cohort. Am J Epidemiol 2009; 169(4): 489-96. https://doi.org/10.1093/aje/kwn348

[78] Bagepally BS, Balachandar R, Kalahasthi R, Tripathi R, Haridoss $\mathrm{M}$. Association between aluminium exposure and cognitive functions: A systematic review and meta-analysis. Chemosphere 2021; 268: 128831. https://doi.org/10.1016/i.chemosphere.2020.128831

[79] Zhang T, He F, Lin S, Wang X, Li F, Zhai Y, et al. Does aluminum exposure affect cognitive function? a comparative cross-sectional study. PLoS One 2021; 16(2): e0246560. https://doi.org/10.1371/journal.pone.0246560

[80] Huat TJ, Camats-Perna J, Newcombe EA, Valmas N, Kitazawa M, Medeiros R. Metal Toxicity Links to Alzheimer's Disease and Neuroinflammation. J Mol Biol 2019; 431(9): 1843-68. https://doi.org/10.1016/j.jmb.2019.01.018

[81] Andrews SJ, Fulton-Howard B, O'Reilly P, Marcora E, Goate AM, collaborators of the Alzheimer's Disease Genetics Consortium. Causal Associations Between Modifiable Risk Factors and the Alzheimer's Phenome. Ann Neurol 2021; 89(1): 54-65. https://doi.org/10.1002/ana.25918

[82] Matthews FE, Arthur A, Barnes LE, Bond J, Jagger C, Robinson $\mathrm{L}$, et al. A two-decade comparison of prevalence of dementia in individuals aged 65 years and older from three geographical areas of England: results of the Cognitive Function and Ageing Study I and II. The Lancet 2013; 382(9902): 1405-12. https://doi.org/10.1016/S0140-6736(13)61570-6

[83] Qiu C, Strauss E von, Bäckman L, Winblad B, Fratiglioni L. Twenty-year changes in dementia occurrence suggest decreasing incidence in central Stockholm, Sweden. Neurology 2013; 80(20): 1888-94. https://doi.org/10.1212/WNL.0b013e318292a2f9

[84] Langa KM, Larson EB, Crimmins EM, Faul JD, Levine DA, Kabeto MU, et al. A Comparison of the Prevalence of Dementia in the United States in 2000 and 2012. JAMA Inter Med 2017; 177(1): 51-8. https://doi.org/10.1001/jamainternmed.2016.6807
[85] Reed BR, Mungas D, Farias ST, Harvey D, Beckett L, Widaman $\mathrm{K}$, et al. Measuring cognitive reserve based on the decomposition of episodic memory variance. Brain 2010; 133(8): 2196-209. https://doi.org/10.1093/brain/awq154

[86] Serra L, Bruschini M, Di Domenico C, Gabrielli GB, Marra C Caltagirone $\mathrm{C}$, et al. Memory is Not Enough: The Neurobiological Substrates of Dynamic Cognitive Reserve. J Alzheimer's Dis 2017; 58(1): 171-84 https://doi.org/10.3233/JAD-170086

[87] Maiovis P, loannidis P, Gerasimou G, Gotzamani- Psarrakou A Karacostas D. Cognitive Reserve Hypothesis in Frontotemporal Dementia: Evidence from a Brain SPECT Study in a Series of Greek Frontotemporal Dementia Patients. NDD 2018; 18(2-3) 69-73.

https://doi.org/10.1159/000486621

[88] Stern Y, Arenaza-Urquijo EM, Bartrés-Faz D, Belleville S, Cantilon M, Chetelat G. Reserve, Resilience and Protective Factors PIA Empirical Definitions and Conceptual Frameworks Workgroup. Whitepaper: defining and investigating cognitive reserve, brain reserve, and brain maintenance [published online September 14, 2018]. Alzheimers Dement 2018; 16(9): 1305-11. https://doi.org/10.1016/j.jalz.2018.07.219

[89] Perneczky R, Kempermann G, Korczyn AD, Matthews FE, Ikram MA, Scarmeas $\mathrm{N}$, et al. Translational research on reserve against neurodegenerative disease: consensus report of the International Conference on Cognitive Reserve in the Dementias and the Alzheimer's Association Reserve, Resilience and Protective Factors Professional Interest Area working groups. BMC Med 2019; 17(1): 47.

https://doi.org/10.1186/s12916-019-1283-z

[90] Arenaza-Urquijo EM, Przybelski SA, Lesnick TL, Graff-Radford J, Machulda MM, Knopman DS, et al. The metabolic brain signature of cognitive resilience in the $80+$ : beyond Alzheimer pathologies. Brain 2019; 142(4): 1134-47. https://doi.org/10.1093/brain/awz037

[91] Kajitani S, Sakata K, Mckenzie C. Occupation, retirement and cognitive functioning. Ageing Soc 2017; 37(8): 1568-96. https://doi.org/10.1017/S0144686X16000465

[92] Grotz C, Meillon C, Amieva H, Stern Y, Dartigues J-F, Adam S, et al. Why is later age at retirement beneficial for cognition? Results from a French population-based study. J Nutr Health Aging 2016; 20(5): 514-9. https://doi.org/10.1007/s12603-015-0599-4

[93] Hill AB. The environment and disease: association or causation? Sage Publications 1965. https://doi.org/10.1177/003591576505800503

\section{https://doi.org/10.6000/2292-2598.2022.10.01.3}

(C) 2022 Juergen Gallistl; Licensee Lifescience Global.

This is an open access article licensed under the terms of the Creative Commons Attribution License (http://creativecommons.org/licenses/by/4.0/) which permits unrestricted use, distribution and reproduction in any medium, provided the work is properly cited. 